PREPARED FOR THE U.S. DEPARTMENT OF ENERGY, UNDER CONTRACT DE-AC02-76-CHO-3073

PPPL-2822

PPPL-2822

UC-420,427

\title{
THEORY AND APPLICATION OF MAXIMUM MAGNETIC ENERGY IN TOROIDAL PLASMAS
}

BY

T.K. CHU

February 1992

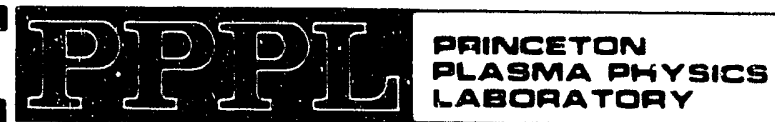

\section{hagopatopr}

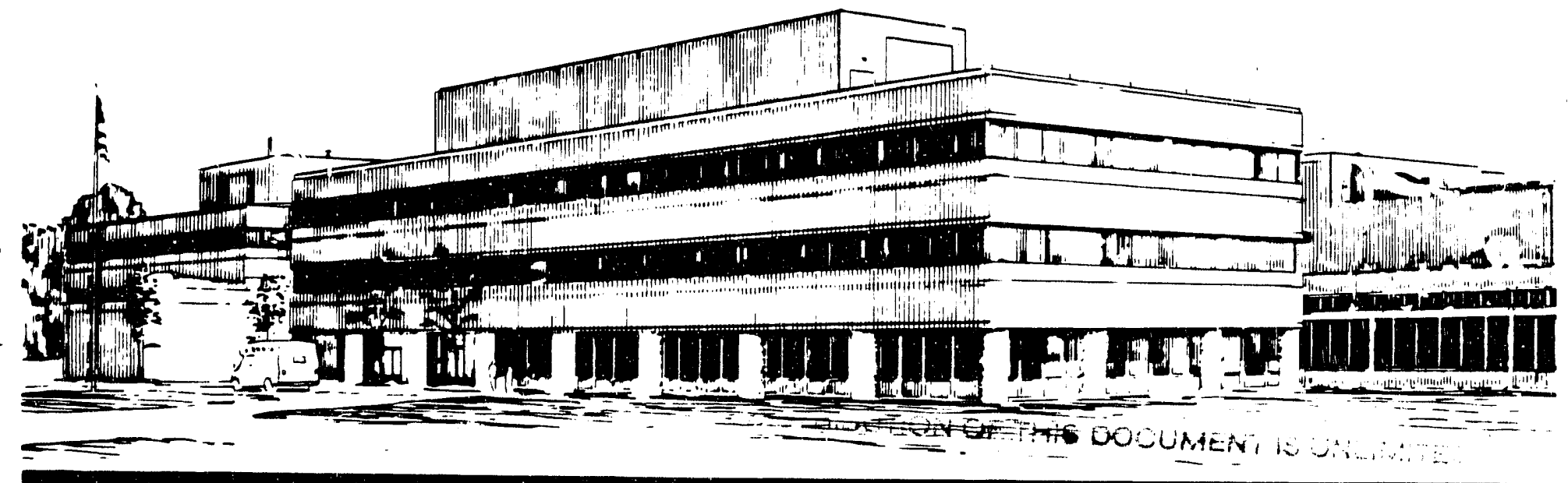

\section{PRINCĚ́tON UNIVERSITY, PRINCETON, NEW JERSEY}


Theory and application of maximum magnetic energy in toroidal plasmas

PPPL --2822

by

DE92 008506

T. K. Chu

Plasma Physics Laboratory, Princeton University

Princeton, New Jersey 08543

The magnetic energy in an inductively driven steady-state toroidal plasma is a maximum for a given rate of dissipation of energy (poynting flux). A purely resistive steady state of the piecewise force-free configuration, however, cannot exist, as the periodic removal of the excess poloidal flux and pressure, due to heating, ruptures the static equilibrium of the partitioning rational surfaces intermittently. The rupture necessitates a plasma with a negative $q^{\prime} / q$ (as in reverse field pinches and spheromaks) to have the same $\alpha$ in all its force-free regions and with a positive $q^{\prime} / q$ (as in tokamaks) to have centrally peaked $\alpha ' s$.

PACS numbers: $52 . \therefore 5 \mathrm{Fa}, 41.10-j, 47.25-\mathrm{c}$, and $52.55 \mathrm{HC}$

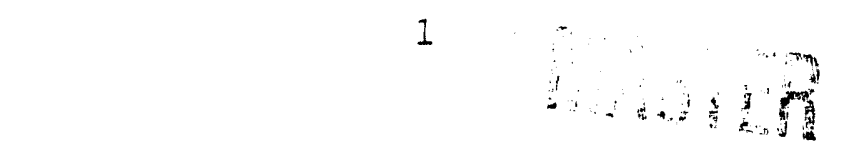

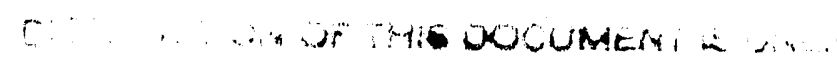


To illustrate the notion of maximum magnetic energy in a driven, current-carrying plasma, consider several resistors (current filaments) carrying parallel current and dissipating energy at a constant rate $V_{L} I_{p^{\prime}}$ where $V_{L}$ is the voltage of the common battery and $I_{p}$ is the total current. The filaments attract and, when unconstrained, move toward one another, resulting in an ever higher magnetic energy. At the steady state (the state of no motion or, more loosely defined, no timeaveraged displacement), the current distribution is a deltafunction line curcent and the stored magnetic energy is the highest. In an inductively driven toroidal plasma, $V_{L}$ is the loop voltage. If an additional constraint exists so that the distribution of the current density cannot reach the deltafunction limit, this constraint sets the limit of (the highest attainable) magnetic energy.

No pressure gradient exists in a force-free region. A tokamak plasma shows a pressure gradient in the entire cross section, indicating that magnetic surfaces marking different force-free regions ${ }^{1}$ (with different $\alpha^{\prime} s$ ) exist in some manner. If the neoclassical transport of pressure across these surfaces is slow, the plasma pressure $p$ can be approximated as being discontinuous across the surfaces as well. The present work proposes that a tokamak plasma is piecewise force-free with its 
rational surfaces being the surfaces of discontinuity, since field line reconnection ${ }^{2,3}$ can transport any unbalanced pressure and poloidal flux and thus restores equilibrium of the surfaces.

Plasma equilibrium is trivially satisfied in force-free regions. The static equilibrium of a surface, on which a sheet current flows, 4 is determined by pressure balance. In cylindrical geometry, components of the surface current, determined by the discontinuity of the field across the surface, are

$$
I_{s \theta}=\lim _{\Delta r \rightarrow 0} j_{s} \Delta r=-\left(\partial B_{\phi} / \partial r\right) \Delta r=B_{\phi 1}-B_{\phi 2}
$$

and $I_{s \phi}=B_{\theta 2}-B_{\theta 1}$. The static equilibrium is achieved when $\left(p_{1}-p_{2}\right)=I_{s \phi^{B} \theta}-I_{s \theta^{B}}{ }_{s \phi}$. (In a toroidal plasma, add the secondary current so that $\left.\nabla \cdot j_{s, \text { total }}=0.\right)$ Use $B_{s \phi}=\left(B_{\phi 1}+B_{\phi 2}\right) / 2$ and $B_{s \theta}=\left(B_{\theta 1}+B_{\theta 2}\right) / 2$ to obtain

$$
\left(p_{1}-p_{2}\right)=\left(B_{\phi_{2}}^{2}-B_{\phi_{1}}^{2}\right) / 2+\left(B_{\theta 2}^{2}-B_{\theta 1}^{2}\right) / 2 .
$$

Equation (2) can also be obtained from surface integrals (with $\boldsymbol{B} \cdot \boldsymbol{n}=0$ on $S)$ of the equations $\nabla p=j \times \boldsymbol{B}, \quad \nabla \times \boldsymbol{B}=\boldsymbol{j}$ and $\nabla \cdot \boldsymbol{B}=0$. The ratio of supply rates of energy to helicity to a forcefree region between two surfaces is ${ }^{1}$ 


$$
\alpha\left(q_{S^{\prime}}\right)=\frac{\int_{S^{\prime}-S^{\prime}}, E \times B \cdot n d S}{2 \int_{S^{\prime}-S^{\prime}}, E \times A \cdot n d S},
$$

where each integral is the difference of two surface integrals evaluated on $S^{\prime}$ and $S^{\prime \prime}, \Delta r$ apart. Approximate $j$ as being constant over $\Delta r$. Hence, $\alpha\left(q_{S^{\prime}}\right) \approx \alpha(r)$, where

$$
\alpha(r) \approx \frac{V_{L} j(r)}{2 V_{L} B_{\phi}}=\frac{j(r)}{2 B_{\phi}} .
$$

The constant-j approximation, however, results in a loss of information on the structure of the field within a force-free region (Ampere's law requires nonuniform field in a force-free region of finite domain). Note that $\alpha_{0} \equiv \alpha(0)=1 / q_{0} R_{0}$ (an exact relation), where $R_{0}$ is the major radius. When the small variation in $B_{\phi}[$ in Eq. (2)] is neglected, $\alpha(r) \propto j(r)$. Thus, the total rate of energy dissipation (for a given rate of helicity dissipation) over the radius $a$ becomes

$$
V_{L} I_{p}=V_{L} \int_{0}^{a} 2 \pi r j(r) d r
$$

The problem is to find the maximum energy, subject to this constraint - equivalently, the constraint of constnt $I_{p}$. 
In each force-free region, $B_{\phi}$ and $B_{\theta}$ are related through the force-free condition. $\quad\left(B_{r^{\prime}}\right.$ if finite, is assumed negligible by comparison.) Choose $B_{\theta}$ as the independent parameter. Use the variational method with a Lagrange multiplier, $\lambda^{\prime}$, and obtain

$$
\delta W=\delta \int_{0}^{a} 2 \pi r\left[B_{\theta}^{2} / 2+p /(\gamma-1)-\lambda^{\prime} j\right] d r=0
$$

Next, relate $p$ to $\alpha$. With negligible radiative and neoclassical pressure transport, the sustaining influx is helicity (and the accompanying poynting flux to dissipate this helicity supply) and the final outward flux, due to dissipation, must be a net flow. The variation of $p / \alpha$ is given by

$\partial(p / \alpha) / \partial t+\nabla \cdot\left(\Gamma_{\text {in }}+\Gamma_{\text {out }}\right)=0$. With $\partial(p / \alpha) / \partial t=0$, the ratio of the fluxes governing $p / \alpha$ is a constant. Integrate the pressure balance equation, (3/2) $\boldsymbol{v} \cdot \nabla p+(5 / 2) p \nabla \cdot v=\mathbf{E} \cdot \mathbf{j}$, where $\checkmark$ is the plasma flow velocity, and obtain

$$
p=-(4 \alpha / 5) \frac{\int_{S^{\prime}-S^{\prime}} \operatorname{EXA\cdot ndS}}{\int_{S^{\prime}-S^{\prime}}, v \cdot n d S} .
$$

\footnotetext{
Hence, $p$ is proportional to $\alpha$. [For ].arge neoclassical transport, as in a highly collisional plasma, or large radiative loss, Eq. (7) becomes a poor approximation.]
} 
A contradiction in the bounciary conditions arises. While the force-free configuration requires $\boldsymbol{B} \cdot \boldsymbol{n}=0$, the pressure transport requires $\boldsymbol{v} \cdot \boldsymbol{n} \neq 0$. (The net flow is associated with the $\operatorname{term} \int_{S} \boldsymbol{B}(\boldsymbol{B} \cdot \boldsymbol{\Omega}) d S$ when $\left.\boldsymbol{B} \cdot \boldsymbol{n} \neq 0.\right]$ Thus, the two processes must occur alternately, as exemplified in the easily observed sawtooth oscillations, and there is no purely resistive steady state. The rupture removes the excess pressure and poloidal flux so that the equilibrium is restored. The validity of Eq. (7) requires the periodicity of the rupture be much shorter than the time needed for neoclassical and radiative transport to flatten the pressure gradient at a surface.

Return to the variational problem. Define $\Psi$ by $B_{\theta}=d \Psi / d r$ and $\Psi^{\prime} \equiv d \Psi / d r^{2}=(1 / q) B_{\phi} / R_{0}$. With $p \propto \alpha \propto j$, the variation, together with the boundary condition $\delta \Psi=0$, requires $j \propto \mathrm{e}^{\Psi \pi \lambda}$, where $\lambda$ is a constant (Lagrange multiplier). Use this $j$ to solve for $\Psi$ and obtain

$$
j / j_{0}=p / p_{0}=\frac{1}{\left[1+\left(q_{a} / q_{0}-1\right)\left(r^{2} / a^{2}\right)\right]^{2}}
$$

and $\left(q_{0^{\prime}} q\right)^{2}=j / j_{0}$. The profile is continuous in rational number space, henct coarse-grain'd in rhysical space, as observed. ${ }^{5-7}$ Equation ( 8 ) hi's beer. ofcained by several authors, $8-10$ but based 
on the concept of minimum energy, not that of maximum energy in a driven plasma. Also, for that reason, the condition governing $q_{0}$ could not be formulated.

In the limit of $q_{0} \rightarrow 0, j$ in Eq. (8) approaches a diltafunction line current at the magnetic axis. The constraint that limits $q_{0}$ to a nonzero value is $\partial p / \partial r=0$ at $r=0$.

Mathematically, the result can be found from the general forcefree configuration that includes the magnetic axis. The toroidal force-free configuration associated with the $q_{s}=1$ surface for plasmas having a circular cross section has been obtained by Hastie ${ }^{11}$ (to the order $a^{3} / R_{0}{ }^{3}$ ):

$$
q \approx q_{0}\left[1+\left(r^{2} / R_{0}^{2}\right)\left(29 / 32-1 / 2 q_{0}^{2}\right)\right]
$$

[Eq. (9) is applicable to the region $r<r_{1}$ if the region has a constant $\alpha$. However, this is not the case. Since $r_{1} / R_{0} \sim 0.1$ in tokamak plasmas, Eq. (9) gives $q_{0} \approx .996$, much higher than measured values.] As $r \rightarrow 0$, it gives the desired result. The lowest $q_{0}$ below which a monotonically increasing $q$ profile (as in tokamak plasmas) is no longer possible is $q_{0}=.743$. The profile in Eq. (8) is thus fully determined.

The following are some consequences of the profile.

1. The profile of dissipation. Since $\alpha(r) \approx j(r) / 2 B_{\phi^{\prime}}$ the 
rate of dissipation of energy varies as $f(r)$ (while that of helicity as $B_{\phi^{\prime}}$ a constant). The heating rate increases with decreasing $r$; the static equilibrium of a surface cannot be maintained.

2. The boundary condition for p. Apply Eq. (2) to the outermost magnetic surface. When $p_{1}$ is raised, $p_{2}$ also must be raised. Hence, a plasma vacuum $\left(p_{2}=0\right)$ cannot support an equilibrium.

3. Position of the $q_{s}=1$ surface. Set $q=1$ for $r=r_{1}$ and $q_{0}=.743$ in Eq. (8) and obtain

$$
r_{1} / a=\frac{0.51}{\left(q_{a}-.743\right)^{1 / 2}}
$$

This cylindrical-geometry result agrees with measured inversion radil of chordal soft $\mathrm{X}$-ray emissions of sawtooth oscillations, $r_{\text {inv' }}$ in TFTR ${ }^{12}$ (Tokamak Fusion Test Reactor) and TEXT'13 (Texas Tokamak) plasmas having $q_{a} \leq 4$, and up to $\sim 60 \%$ higher than measured $r_{\text {inv }}$ for increasingly higher $q_{a}$. (The tokamak at Fontenay-aux-Roses, TER, shows that $r_{1}$ is up to 1.7 times of $r_{\text {inv }}{ }^{14}$ ) It also apparently agrees with the TFR results, 15 described by the empirical. formula $r_{1 n v} / a=0.5 f\left(q_{0}, q_{a}\right) / q_{a}^{1 / 2}$, with $f$ being between .5 and 1 .

4. The origin of sawtooth oscillations and concept of an instability. After an internal disruption, $j_{0}$ once more 
increases in time and $q_{0}(t)=q_{0}(0)+\left(d q_{0} / d t\right) t$. The inductance change in the region $r<r_{1}$ gives $d q_{0} / d t=-4 V_{\text {ind }} / \mu_{0} I_{1} R_{0} f_{1}\left(q_{0}\right)$, where $V_{\text {ind }}$ is the inductive part of the loop voltage at $r=0$, $I_{1}=2 \pi r_{1}^{2} B_{\phi} / \mu_{0} R_{0}$, and $f_{1}\left(q_{0}\right)=\left[\ln q_{0}^{2}+2\left(1-q_{0}\right)+\left(1-q_{0}\right)^{2} / q_{0}\right] /\left(1-q_{0}\right)^{3}$. The time required for $q_{0}$ to attain the value .743 from $q_{0}(0)$ is (approximately) the sawtooth period. Sawtooth oscillations are driven by the toroidal electric field which pinches the current channel till the limit $q_{0}=.743$. Their period increases with a lowered loop voltage. They are suppressed (disappear) when the voltage becomes zero.

Below the limit $q_{0}=.743$, toroidal symmetry of the magnetic axis no longer can be maintained; a helical displacement and plasma motion is generally observed. In the past, a plasma is thought to become unstable when it no longer can maintain a minimum-energy equilibrium. The present theorem inevitably advances the concept that an instability in a plasina, which is driven, is a symmetry-breaking expression in the process of attaining a higher energy as dictated by the driving potential. An ever higher energy can be attained by breaking more symmetry constraints. [A simple one-dimension mechanical analog is a violin string which also undergoes sawtooth oscillations when bowed unidirectionally. In a sawtooth cycle, the string, after the loss of static equilibrium in its slipping from the hair, 
continues on to attain higher potential energy (till the ultimate snapback).] Intuitively, one may also expect a correspondence between the structure of the broken symmetry and the throughput from the source and the energy in the plasma.

5. J profile. Figure 1 shows a comparison of measured $j$ profiles in the TEXTOR tokamak with Eq. (8) (solid curve). The profile shapes agree. $q_{0}=.743$ also results in $j_{0} /\left(B_{\phi} / R_{0}\right)=2.69$; the measured value is $2.62 \pm .20$ (Fig. 6, Ref. 5).

6. p profile. The local scale length of the pressure gradient, ${ }^{16} L_{p} \equiv-p / \nabla p$, can be used to characterize a pressure profile and to bypass its normalization by $p_{0}$. Figure 2 shows the $\bar{a} / I_{p}$ profile constructed from measured $T_{e}$ and $n_{e}$ of the $H^{-}$ mode plasma (in which the effective collision frequency $v_{e}{ }^{*}$ in the edge region is much less than unity ${ }^{16}$ ) produced by electron cyclotron heating in the D-III D tokamak. ${ }^{17}$ In the experiment $T_{i}$ is a fraction of $T_{e}$ and $Z_{\text {eff }}(\approx 2.5)$ is nearly uniform in the cross section, justifying the use of $L_{p} \approx L_{p e}$. The rise of $\bar{a} / I_{p}$ at the edge is due to the drop of $T_{e}$ and $n_{e}$ beyond the edge. The shape of the two pressure profiles agrees, but in the sawtoothing core the measured values are trending towards values that are increasingly lower than those from Eq. (8). Comparison can also be made in L-mode plasmas in sawtooth- 
suppression experiments with lower hybrid waves ${ }^{18}$ in the ASDEX tokamak. ${ }^{7}$ Figure 3 , curve $a$, shows the $a / I_{p}$ profile for a plasma in which sawtooth oscillations are suppressed during the wave $\left(t_{r f}=.5 \mathrm{sec}, P_{r F}=1.1 \mathrm{MW}\right)$ and only a small restdue of the $m=1$ mode is left $i^{18}$ and $V_{L}$ at the plasma surface is fintte. This profile agrees with that of Eq. (8), unlabelled curve, for $r / a<.6$. The ohmically heated sawtoothing plasma, curve $b$, does not. In both cases, $a / I_{p}$ rises to $\sim 16$ at the edge. (The onmically heated and the I-mode profiles of the DIII-D experiment ${ }^{17}$ are similar to curve b of $\mathrm{E} \pm \mathrm{g}$. 3.) Thus, when compared to Eq. (8), $p$ in the edge of an L-mode plasma is lower because of the high collisional and radiative transport; $\nabla p$ in the core is lower because of the sawtooth oscillations. (Let $\tau_{q_{0}}$ be the time for $q_{0}$ to be lowered by $\Delta q_{0}=q_{0}(0)-.743$ after an internal disruption, and $\tau_{p_{0}}$ be that for $p_{0}$ to increase, due to heating, to the corresponding limit according to Eq. (8). $\tau_{q_{0} /} \tau_{p_{0}} \approx(2 / 3)\left(\Delta q_{0} / q_{0}\right) /\left(1-q_{0}{ }^{2}\right) \approx 0.2$. Hence, after an internal disruption, $p_{0}$ has not reached its corresponding force-free limit when $q_{0}$ has reached its limit.]

7. The bifurcation of a toroidal plasma. Apply Eq. (9) to an RFP plasma and obtain

$$
q_{a} / q_{0} \approx 1-\frac{\left(\alpha_{0} a\right)^{2}}{2}
$$


[Alternatively, from Eq. (8) obtain $q_{a} / q_{0}=1+a^{2} q^{\prime \prime} / 2 q_{0}$ $\left(q_{a}<q_{0}\right.$ for negative $\left.q^{\prime \prime}\right)$ and use $q^{\prime \prime}$ from Eq. (9) to obtain Eq. (11).] It agrees with measurements, ${ }^{19}$ as shown in Fig. 4 [the so-called $F\left(=q_{a} / q_{0}\right)-\theta\left(=\alpha_{0} a=a / q_{0} R_{0}\right)$ diagram]. Field reversal occurs at $\alpha_{0} a \approx \sqrt{ } 2$.

Both tokamak and REP plasmas have more than one rational surface - both configurations are piecewise force-free. Why centrally peaked $\alpha$ in a tokamak plasma requires monotonically increasing $q$, while an RFP plasma, with decreasing $q$, has the same $\alpha$ in all its force-free regions? Because of heating, maintaining a nonuniform- $\alpha$ profile requires, from time to time, a piecewise net removal - "relaxation" - of excess poloidal field and pressure from an inner force-free region to the adjacent outer one so that equilibrium of the separating surface can be restored. At a rational surface $q_{s}$, this removal is accomplished by a reconnection of the field lines. Define $\Psi_{h}$ by $B_{h}=d \Psi_{h} / d r$, where the helical field, $B_{h}$, at a distance $\Delta r$ away from the $q_{s}$, is given by $B_{h}=B_{\theta}-n q B_{\phi} / m=-B_{\theta}\left(q^{\prime} / q\right)_{s} \Delta r$. During the reconnection,

$$
\partial B_{h^{\prime}} \partial t=-B_{\theta}\left(q^{\prime} / q\right)_{s} V_{r}
$$


where $V_{n}$, is the velocity at which the helical flux (and therefore the poloidal flux) is carried by the plasma towards the $\mathrm{x}$-point where it is to be reconnected. $V_{t}$ is positive pointing outward) for the inner force-free region and negative for the neighboring outer one. For $q>0$, any unbalanced interior poloidal flux is removable only for positive $q^{\prime}$. Hence, $q_{0}=.743$ marks the bifurcation of a toroidal plasma: because of surface rupture, those with monotonically decreasing $q$ land hence $q_{0}<.743$ ) have the same $\alpha$ in all its force-free regions and with monotonically increasing $q$ (and hence $q_{0}>.743$ ) have centrally peaked $\alpha$. For $q$ and $q^{\prime}$ both nerative, as in the edge region of an REP plasma beyond the internal reversal point, $\alpha$ increases towards the interior, as observed. ${ }^{20}$ The spheromak configuration, with $q>0$ and $q^{\prime}<0$ throughout, has the same constant $\alpha$ in all its force-free regions.

In summary, the magnetic energy of an inductively driven steady-state toroidal plasma is a maximum for a given rate of energy dissipation (a given constant poynting flux at the boundary). Its configuration is piecewise force-free: it consists of nested, toroidally symmetric and noninfinitesimal regions that are separately force-free. The static equilibrium of the boundary between two adjacent regions is maintained by a pressure balance across the boundary. Because of heating, the 
partitioning rational surfaces rupture intermittently. A tokamak plasma has centrally peaked $\alpha^{\prime} s$ in its piecewise forcefree regions. This is because it has a positive $q^{\prime} / q$, which allows a piecewise outward-removal of the unbalanced flux and pressure and the restoration of equilibrium of a partitioning surface. In a toroidal plasma havins a negative $q^{\prime} / q$, such a piecewise outward-removal is not possible and all its force-free regions must have the same time-averaged $\alpha$.

ACKNOWLEDGEMENT. I benefited from discussions with wolfgang Stodiek, Allan Reiman, Shoichi Yoshikawa, Martin Kruskal, and Raffi Nazikian. The permission from Dieter Murmann of the ASDEX group at the Max-Planck Institut für Plasmaphysik to use the YAG-laser scattering data for constructing Eig. 3 is gratefully acknowledged. This work is supported by U. S. Department of Energy Contract No. DE-ACO2-76-CHO 3073. 


\section{References}

1 T. K. Chu, "Theory of minimum dissipation of energy for the steady state," Princeton Plasma Physics Laboratory Report PPPL-2821, December 1991 (submitted to Phys. Fluids).

2 H. P. Furth, J. Kileen, and M. N. Rosenbluth, Phys. Fluids, 6, 459, (1963).

3 B. B. Kadomtsev, Fiz. Plazmy 1, 710 (1975) [Sov. J. Plasma Phys. 1, 389 (1975)]; also, in Plasma Physics and Controlled Nuclear Fusion Research 1976, Berchtesgaden (IAEA, Vienna, 1977), Vol. 1, p. 555.

4 A. Reiman, Phys. Fluids 23, 230 (1980); 24, 956 (1981).

5 H. Soltiwisch, W. Stodiek, J. Manickam, and A. Schlüter, in Plasma Physics and Controlled Nuclear Fusion Research 1986, Kyoto (IAEA, Vienna, 1987) Vol. 1, p 263.

6 B. Grek, D. Johnson, W. Park, G. Taylor, K. McGuire, D. Mansfield, H. Park, Eull. Am. Phys. Soc. 34, 1965 (1989).

7 T. K. Chu, H. Murmann, R. Bartiromo, F. Leuterer, E. Söldner, the ASDEX Team, the Frascati LH Team, and the Princeton LH Team, Bull. Am. Phys. Soc. 34, 1941 (1989).

8 D. Biskamp, Comments Plasma Phys. Controlled Fusion, 10, 165 (1986) .

9 J. Hsu and M. S. Chu, Phys. Eluids 30, 1221 (1987).

10 B. B. Kadomtsev, Comments Plasma Phys. Controlled Fusion, 
11, 153 (1987).

$11 \mathrm{~J}$. Hastie, Nuclear Fusion 29, 96 (1989).

12 M. Murakami, V. Arunasalam, J. D. Bell, M. G. Bell, M. Bitter, W. R. Blanchard, F. Boody, N. Bretz, R. Budny, C. E. Bush, J. D. Callen, J. L. Cecchi, S. Cohen, R. J. Colchin, S. K. Combs, J. Coonrod, S. L. Davis, D. Dimock, H. F. Dylla, P. E. Efthimion, L. C. Emerson, A. C. England, H. P. Eubank, R. Fonck, E. Eredrickson, H. P. Eurth, L. R. Grisham, S. von Goeler, R. J. Goldston, B. Grek, R. Groebner, R. J. Hawryluk, H. Hendel, K. W. Hill, D. L. Hillis, W. Heidbrink, R. Hulse, D. Johnson, L. C. Johnson, R. Kaita, R. Kamperschroer, S. M. Kaye, S. Kilpatrick, H. Kugel, P. H. LaMarche, R. Little, C. H. Ma, D. Manos, D. Mansfield, M. McCarthy, R. T. McCann, D. C. McCune, K. McGuire, D. M. Meade, S. S. Medley, S. L. Milora, D. R. Mikkelsen, D. Mueller, E. Nieschmidt, D. K. Owens, V. K. Pare, H. Park, B. Prichard, A. Ramsey, D. A. Ramussen, M. H. Redi, A. I. Roquemore, P. H. Rutherford, N. R. Sauthoff, J. Schivell, G. I. Schmidt, S. D. Scott, S. Sesnic, M. Schimada, J. E. Simpkins, J. Sinnis, E. Stauffer, J. Strachan, B. Stratton, G. D. Tait, G. Taylor, C. E. Thomas, H. H. Towner, M. Ulrickson, R. Wieland, J. B. Wilgen, M. Williams, K-L.Wong, S. Yoshikawa, K. M. Young, M. C. 
Zarnstorff, S. Zweben, Plasma Physics and Controlled Fusion 28, $17(1986)$.

J. A. Snipes, "The Dynamics of Sawtooth Phenomena in TEXT," Ph. D. Thesis and Eusion Research Center Report No. 275, The Univ, of Texas, Austin, Texas, p.62 (1985).

14 M. A. Dubois, D. A. Marty, and A. Pochelon, Nuclear Fusion 20, $1355(1980)$.

15 Equipe TFR, in Plasma Physics and Controlled Nuclear Fusion Research 1976, Berchtesgaden (IAEA, Vienna, 1977), Vol. 1, p. 279 .

$16 \mathrm{~T} . \mathrm{K}$. Chu, "Comments on experimental results of energy confinement of tokamak plasmas," Princeton Plasma Physics Laboratory Report PPPL-2606, April 1989.

17 John Lohr, B. W. Stallard, R. Prater, R. T. Snider, K. H. Burrell, R. J. Groebner, D. N. Hill, Kyoko Matsuda, C. P. Moeller, T. W. Petrie, H. St. John, and T. S. Taylor, Phys. Rev. Lett. 60, 2630 (1988).

18 S. Bernabei, R. Bell, A. Cavallo, T. K. Chu, P. Colestock, J. Felt, W. Hooke, J. Hosea, F. Jobes, E. Mazzucato, E. Meservey, R. Motley, J. A. Murphy, M. Ono, R. Pinsker, J. Stevens, S. von Goeler, and J. R. Wilson, in Plasma Physics and Controlled Nuclear Fusion Research 1986, Kyoto (IAEA, Vienna, 1987), Vol. 1, p. 503; T. K. Chu, R. Bell, S. Bernabei, A. Cavallo, S. Guharay, W. Hooke, J. Hosea, F. 
Jobes, E. Mazzucato, D. McNeill, E. Meservey, R. Motley, J. Stevens, and S. von Goeler, Nuclear Fusion 26, 666 (1986); T. K. Chu, Bull. Am. Phys. Soc. 31, 1471 (1986) and Nuclear Fusion 28, 1109 (1988).

$19 \mathrm{H}$. Bodin and A. Newton, Nuclear Fusion 20, 1255 (1980).

20 Y. Ueda, N. Asakura, S. Matsuzuka, K. Yamagishi, S. Shinohara, Y. Nagayama, H. Toyama, Nuclear Fusion, 27, 1453 (1987) . 
Figure Captions

Fig. 1. j/ jo vs. $\left(q_{a} / q_{0}-1\right)^{1 / 2} r / a$, Ref. 5: the dashed curve has $q_{a}=3.3, I_{p}=476 \mathrm{kA}, B_{T}=2.51 \mathrm{~T}$; the dotted curve has $q_{a}=3.17, I_{p}=340 \mathrm{kA}, B_{T}=1.7 \mathrm{~T} . R_{0}=1.75 \mathrm{~m}, a=.46 \mathrm{~m}$. The solid curve is Eq. (8).

Fig. 2. $\bar{a} / I_{p}$ vs. $r / \bar{a}$ in an H-mode plasma, Ref. 17 and according to Eq. (8). The measurement used normalized flux coordinate for the D-shaped plasma, somewhat different from the $\bar{a}=\kappa^{1 / 2} a$ used here in Eq. (8), $\kappa=1.8$ being the elongation. $R_{0}=1.68 \mathrm{~m}, a=.62 \mathrm{~m}, I_{p}=.48 \mathrm{MA}, B_{T}=1.07 \mathrm{~T}$, and $\bar{n}_{e} \approx 1.2 \times 10^{19} \mathrm{~m}^{-3}$.

Eig. 3. $a / L_{p}$ vs. r/a in L-mode plasmas, without (curve $a$ ) and with (curve b) sawtooth oscillations. The 16-point YAGlaser scattering profile is fitted with a symmetric exponential function with 4 polynomial terms. $R_{0}=1.65 \mathrm{~m}, a=.40 \mathrm{~m}$, $I_{p}=.42 \mathrm{MA}, B_{T}=2.8 \mathrm{~T}$, and $\bar{n}_{e} \approx 2.8 \times 10^{19} \mathrm{~m}^{-3}$. The unlabelled curve is computed from Eq. (8).

Fig. 4. $q_{a} / q_{0}$ vs. $\alpha_{0} a$ ( $F-\theta$ diagram) in three RFP plasmas, compiled in Ref. 19. The curve is Eq. (11). 


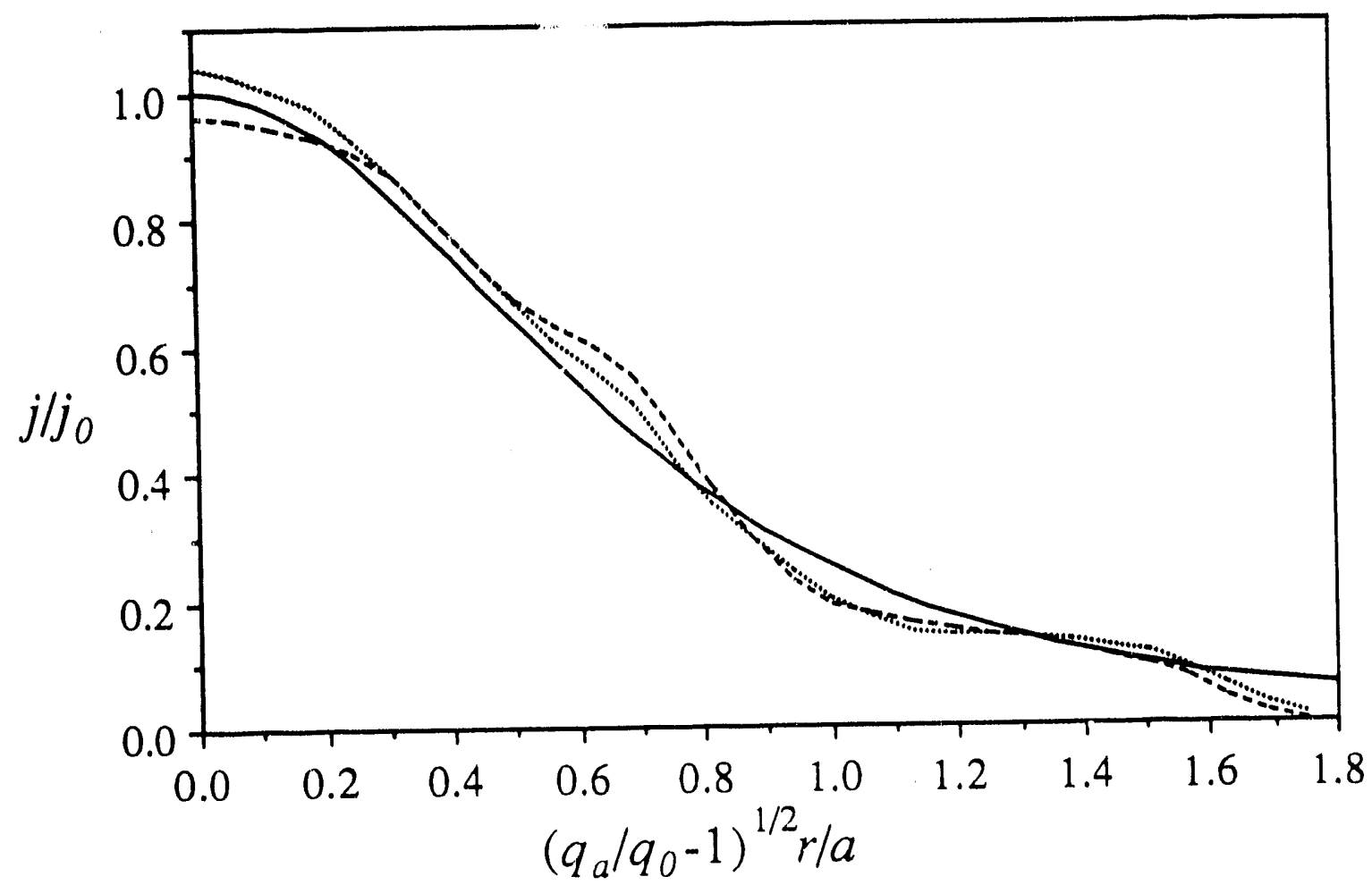

FIg. 1 


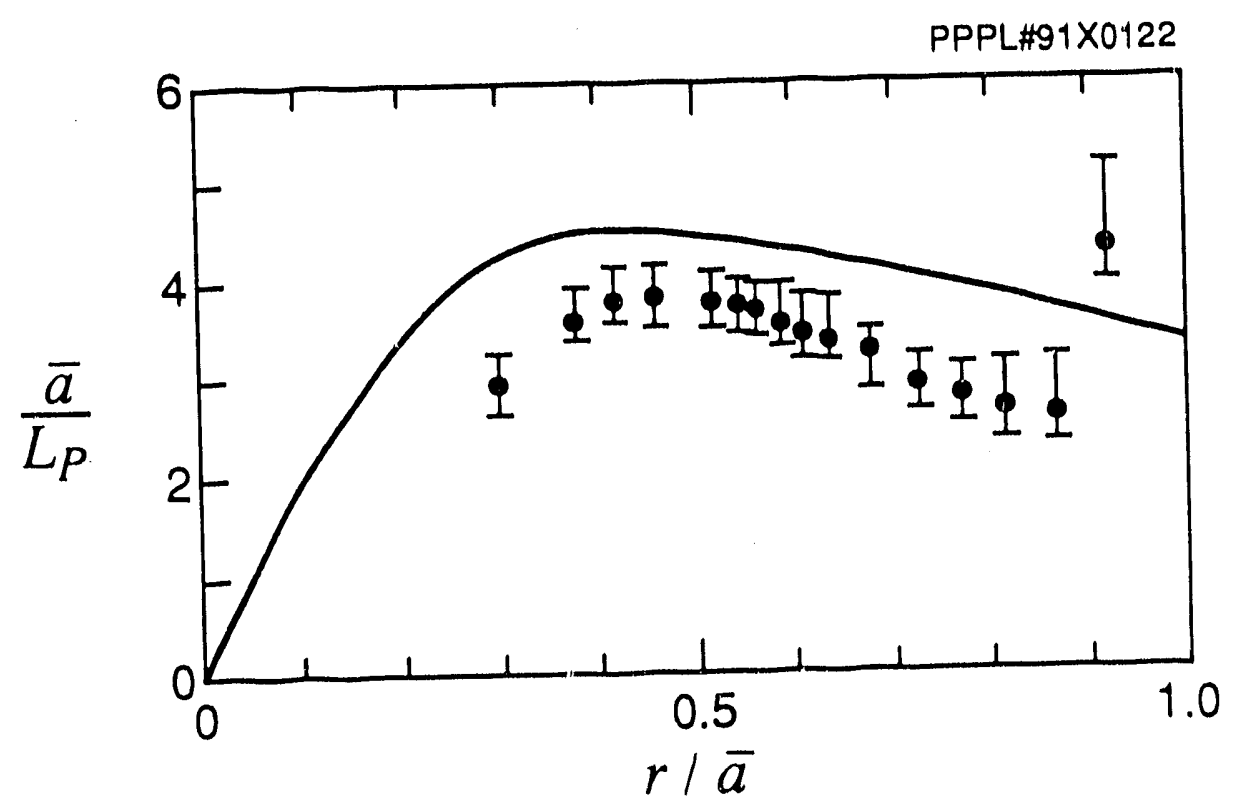

Fig. 2 
$91 \times 3103$

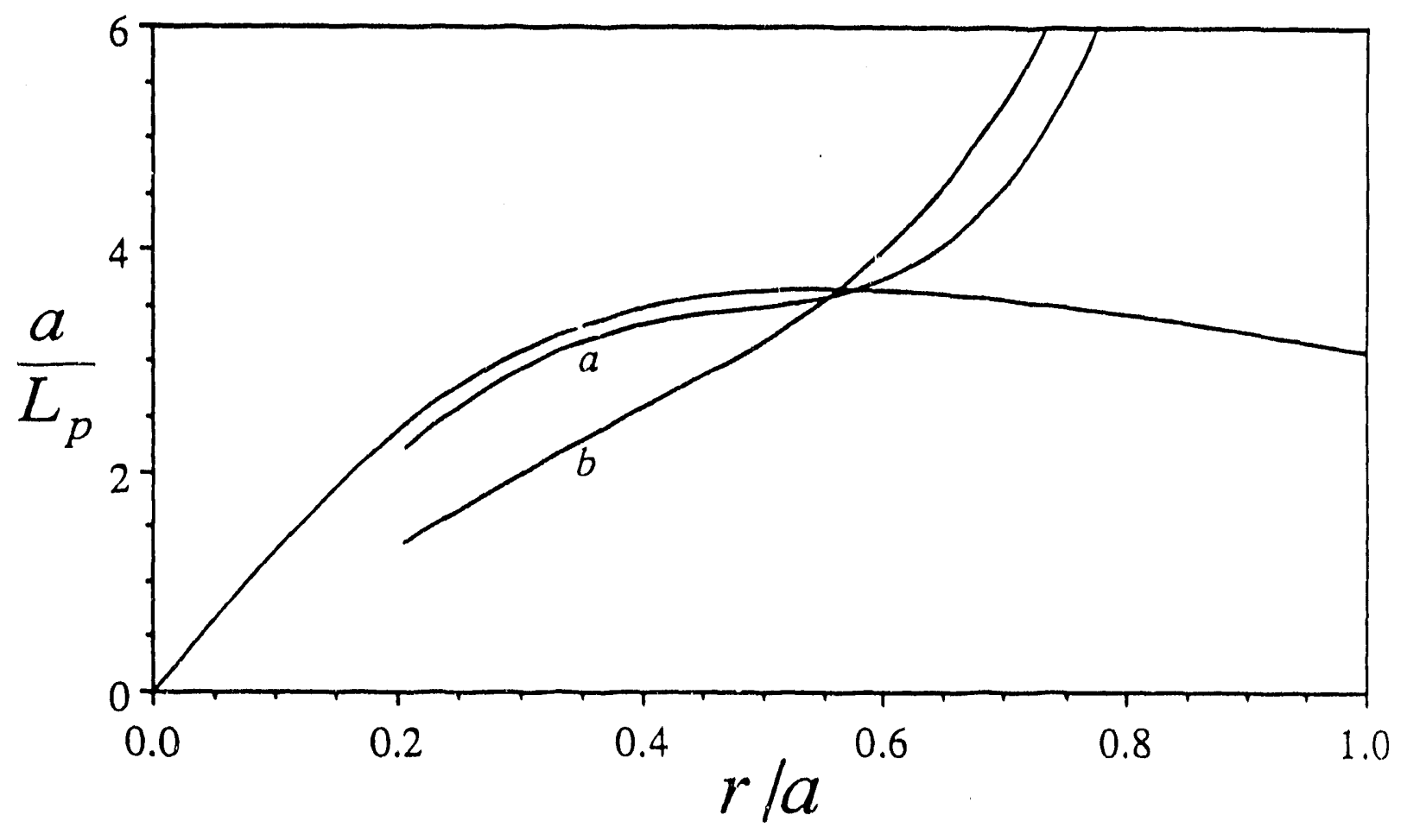

1

Fig. 3 


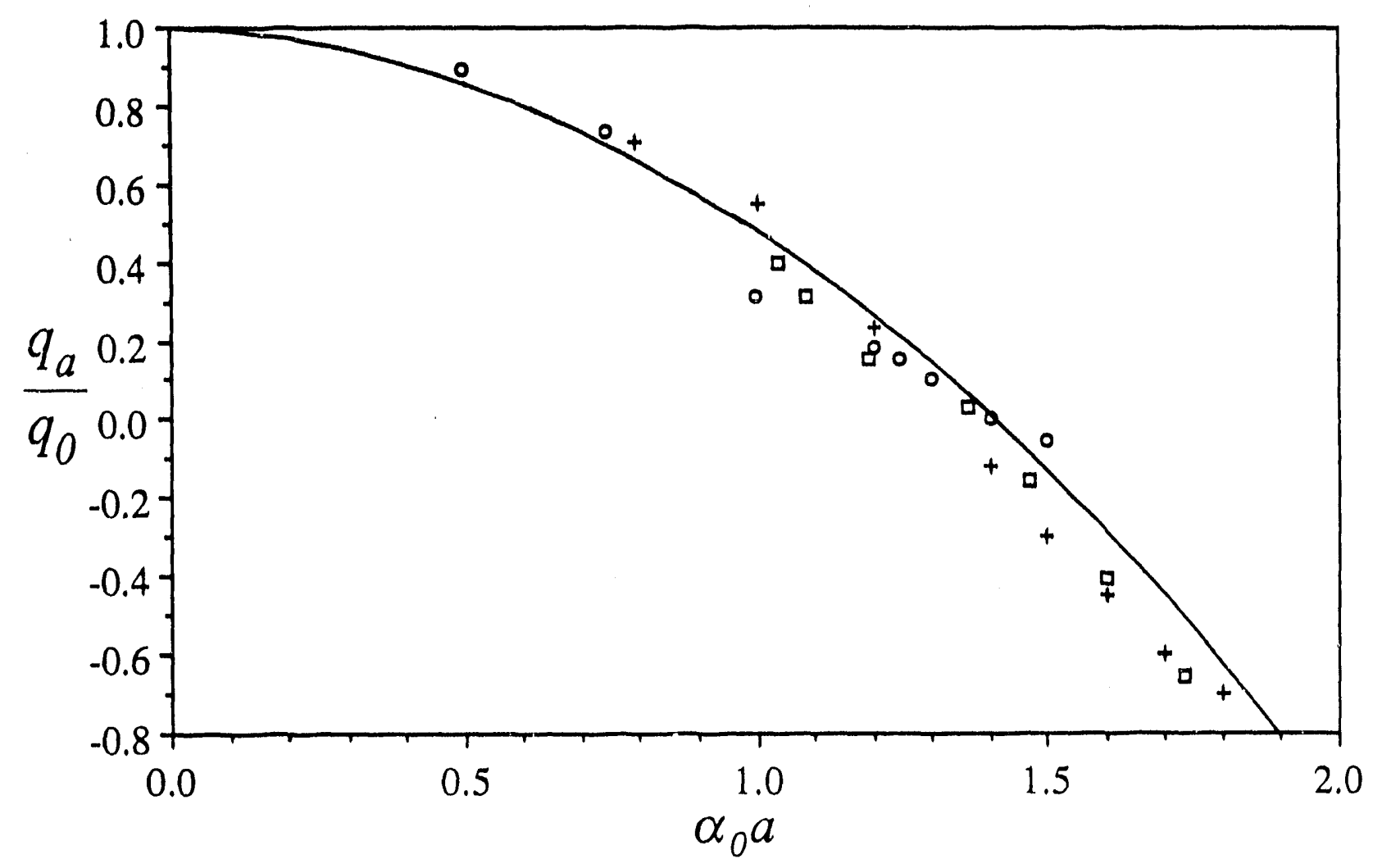

Fig. 4 
Dr, F. Peotoni, Univ, of Wollonoong, AUSTRALIA

Prof. M.H. Brennan, Univ. of Byonoy, AUSTRALIA

Plasma Rosearch Leb., Austrelien Nat. Univ. AUSTRALIA

Prof, I.R. Jones, Findors Univ, AUSTRALIA

Prot, F. Cap, Inst. for Theorotical Physics, AUSTRIA

Prot. M. Hoindlor, Inatiut for Theoretiache Phyalk, AUSTRIA

Prol, M. Goosecons, Actronomicat Inetiuut, BELGIUM

Ecolo Royado Milluiro, Leb. do Pty, Plaemas, BELGIUM

Commisaion-Europen, DG. XII-Fusion Prog., BELGIUM

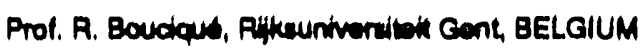

Dr, P.H. Sakenake, Instuto Fiton, BRWZIL

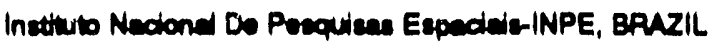

Documents Orilos, Abonic Enerey of Ceneda Lid., CANADA

Dr. M.P. Bechynekd, MPB Technologios, Ino., CANADA

D. H.M. Skeregard, Univ, of Sackatchowen, CANADA

Prof. J. Telchmarm, Utriv, of Montroed, CANADA

Prot. S.R. Siscenturean, Univ, of Celogry, CANADA

Prol. T.W. Johneton, INRS-Energio, CANADA

Dr. R. Botion, Contro canacien do fusion magndtoqu, CANADA

Dr. C.R. Jemee., Univ. of Aberta, CANADA

Dr. P. Luktc, Komentke tho Untweredita, CZECHOSLOVAKIA
The Librarian, Cuthem Leborabry, ENGLAND

Lborary, R61, Ruthertord Apploton Laboratory, ENGLAND

Nrs. S.A. Hulchinsoon, JET Librey, ENGLAND

Dr. S.C. Shame, Univ. of South Pecific, FIJI ISLANDS

P. Munomen, Univ. of Hoisindi, FINLAND

Prot. M.N. Buacesc, Ecob Potylechnious, FRANCE

C. Moutiot, Lab. de Physique des Milloux lonisds, FRANCE

J. Raciat, CENCADARACHE - Bat 506, FRANCE

Prof. E. Economou, Univ. of Crew, GPEECE

Ma. C. Rinni, Univ, of loamina, GREECE

Dr. T. Muel, Acadermy Bibliographic Ser, HONG KONG Preprint Librery, Hungarien Acaderny of Sol. KIUNGARY

Dr. B. Dascupta, Saha Inst of Nucinar Ptysize, INDIA

Dr. P. Kaw, inst. for Plasma Pocearch, INDIA

Dr. P. Rocenew, lereed inst of Technology, ISPAEL

Lborerien, Iniemationd Comber for Theo Phyeice, ITALY

Miss C. Do fialo, Aseociazione EURATOALENEA, ITALY

Dr. G. Groseo, letituto di Fidican ded Pluema, ITALY

Prot. G. Rostenoni, lestuto Gas lonizzati Del Cni, ITALY

Dr, H. Yamaio, Tochiba Rea a Dovel Center, JAPAN
Prot. I. Kewakemi, Hroshima Univ., JAPAN

Prol, K. Nishikewwa, Hroshima Univ., JAPAN

Drector, Jepen Atomic Energy Research Inst, JAPAN

Prof. S. Iroh, Kyustu Univ., JAPAN

Research Info. Ctr, Nations Instt. for Fusion Scienco, JAPAN

Prof. S. Tenaika, Kyoto Univ., JAPAN

Lborm, Kyoto Univ., JAPAN

Prof. N. Inow, Univ, of Tokyo, LAPAN

Socrutery, Plewm Section, Electrowachnical Lab., JAPAN

S, Mori, Technical Advieor, MAEF, JAPAN

Dr. O. Mised, Kumamoto hat. of Tectroktugy, JAPAN

J. Hyeon-Sook, Korea Abomic Energy Ferearch Inst, KOREA

D.I. Chod, Tho Korea Adv. Inat of Sa. Tech., KOREA

Prot. B.s. Liby, Univ, of Welkato, NEW ZEALAND

Inst of Phyila, Chinese Acad SA PEOPLE'S REP. OF CHINA

Litreny, Inst of Plasma Phycics, PEOPLE'S REP. OF CHINA

Tainghua Univ. Librery, PEOPLE'S REPUBLIC OF CHINA

2. U, S.W. Inat Phydia, PEOPLE'S REPUBLIC OF CHINA

Prof. J.A.C. vebred, Inetituto supertor Tecnico, PORTUGAL

Dr. O. Petrus, AL I CUzA Univ., ROMANIA

Dr. J. do Villers, Fusion Studies, AEC, S, AFRICA

Prot. M.A. Hellberg, Univ, of Natul, S. AFRICA

Prot. D.E. Kin, Poheng ind. of Sa. I Tech., SO. KOREA

Prot. C.I.E.M.A.T, Fusion Division LUbrary, SPAIN

Dr. L SEmilo, Univ. of UMEA, SWEDEN

Librery, Royd inat of Tectnology, SWEDEN

Prol. H. Wihatmeon, Cheimors Univ. of Tech., SWEDEN

Centro Phys. Dos Plasmas, Ecole Pohtech, SWITZERLAND Bibliotheax, Inst. Voor Plauma-Fysica, THE NETHERLANDS

Asst. Prot. Dr. S. Cekdr, Midds East Tech. Univ., TURKEY

Dr. V.A. Gukthilwh,Sad. Res. Inst. Electrophys.I Apparatus, USSR

D. D.D. Ayutov, Slberian Brench of Acaderny of SC., USSA

Dr. G.A. Elicen, I.V. Kurchatov Inst, USSA

Librerien, The Ukr.SSR Academy of Scioncos, USSR

Dr. LM Kowizhmykh, Inat. of Gonerd Physica, USSR

Kemtorectungeanleop GmbH, Zentrablbllothek, W. GERMANY Biblothat, Inst. For Plasmator chung, W. GERMANY Prof. K. Schinder, Rutr-Universit Bochum, W. GERMANY Dr. F. Weoner, (ASDEX), Max-Planck-institut, W. GERMANY Librerien, Max-Plenck-Inotitux, W. GERMANY Prof. R.K. Jenow, Inat. of Physica, YUGOSLAVIA 

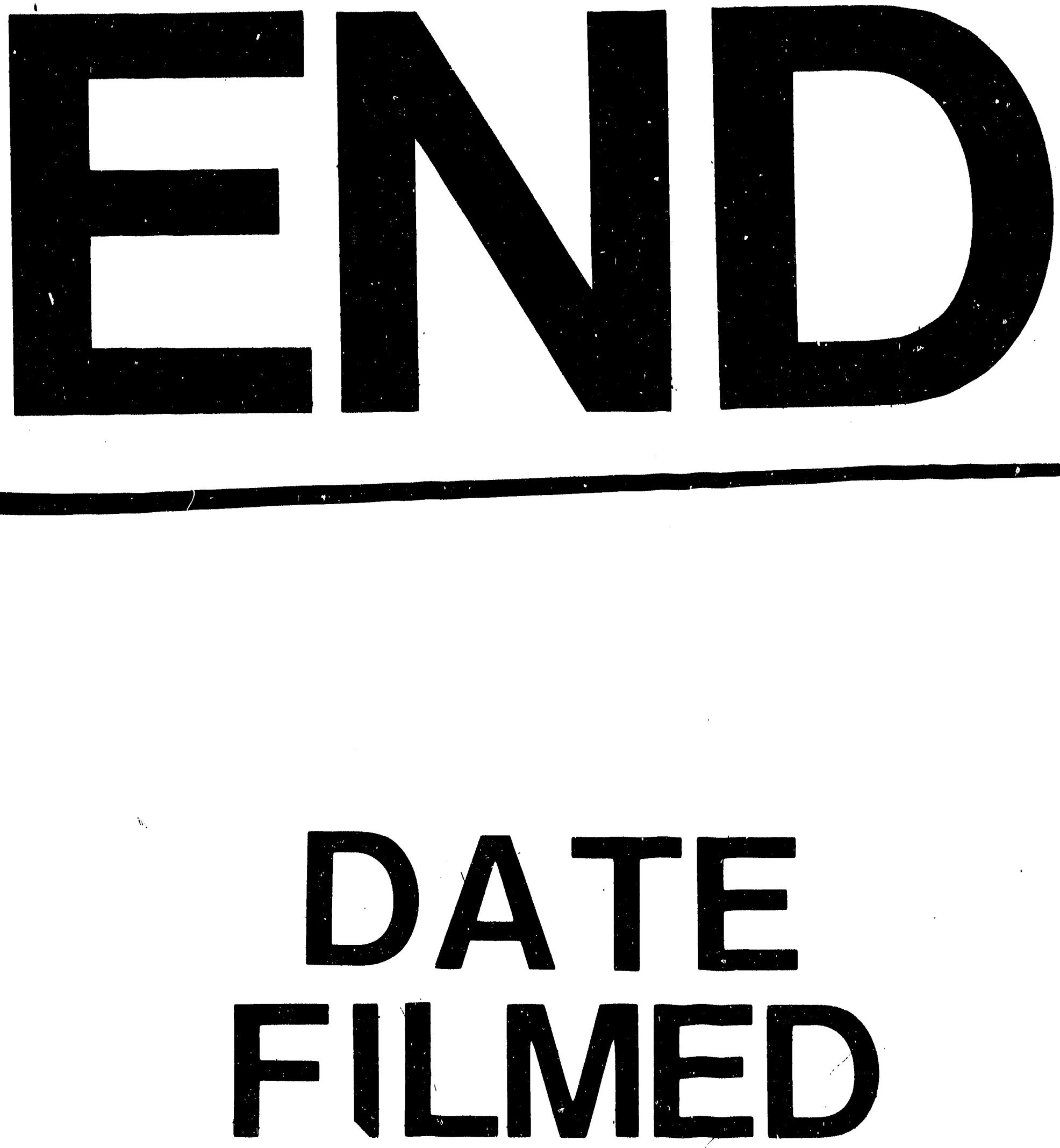

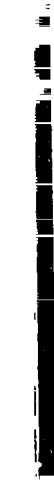

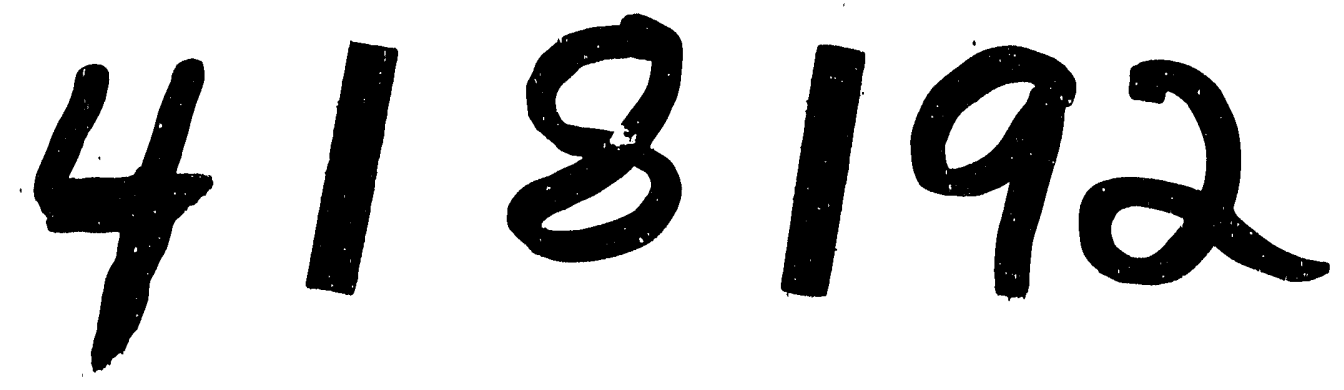

$I$ 